\title{
IGUALDAD SUSTANTIVA EN EL DERECHO DE FAMILIA
}

\section{MARIA DEL ROSARIO MOLINA GONZALEZ ${ }^{1}$ MARIA TERESA GAXIOLA SÁNCHEZ MARCO ANTONIO VELDERRAIN RODRIGUEZ CARLOS ARMANDO TORRES LAGARDA}

\begin{abstract}
Resumen: La familia como grupo primario de organización social, sigue siendo considerada un elemento fundamental e insustituible en la formación de valores y núcleo de integración social, y en ella se encuentra manifestación de los vínculos social, jurídicos, económicos, culturales; en su propia dialéctica el entorno familiar ha mutado su forma nuclear paradigmática -padre, madre, hijos-, en las últimas décadas, en consonancia con los avances de los derechos humanos, la dignidad humana, la inclusión y la tolerancia, se ha ajustado en función la diversidad de las relaciones interpersonales. Ciertamente, al ser la familia la estructura social básica responde a los constructos que, el colectivo de pertenencia, en la época y lugar determinado, orientan y modelan en la construcción de género, de los roles y estereotipos que la femineidad y la masculinidad imponen; no obstante, los avances asincrónicos entre la realidad fáctica y jurídica, han exigido que el propio derecho de familia modifique los criterios de las normas en armonía a esta amplitud y diversidad. El presente trabajo, como resultado parcial de investigación, tiene como objetivo plantear un acercamiento a los avances desde el sistema normativo y jurisprudencial, en torno al derecho de familia y sus adecuaciones atenuar la diferencia de los roles y estereotipos de género, construida como un estudio analítico y descriptivo de las interpretaciones judiciales pro igualdad.
\end{abstract}

\footnotetext{
${ }^{1}$ El presente trabajo es un producto parcial de la Investigación "Igualdad de género en el derecho de familia en Sonora. Indicadores cuantitativos y cualitativos de discriminación indirecta", Con clave de registro USO512001940, realizado por el Cuerpo Académico UNISON-CA-165, en la línea de generación y aplicación del conocimiento: "Tendencias actuales del derecho".
} 
http://revistainvestigacionacademicasinfrontera.com

Palabras clave: Familia, Igualdad, Derecho de familia, Modelos de familia.

Summary: The family as a primary group of social organization continues to be considered a fundamental and irreplaceable element in the formation of values and a core of social integration, and in it there is a manifestation of social, legal, economic and cultural ties; in its own dialectic the family environment has mutated its paradigmatic nuclear form-father, mother, children-and in recent decades, in line with the advances of human rights, human dignity, inclusion and tolerance, has been adjusted depending on the diversity of interpersonal relationships. Certainly, as the family is the basic social structure responds to the constructs that, the collective of belonging, in the time and place determined, guide and model in the construction of gender, the roles and stereotypes that femininity and masculinity impose; nevertheless, the asynchronous advances between the factual and legal reality, have demanded that the family law itself modify the criteria of the norms in harmony to this amplitude and diversity. The present work, as a partial result of research, aims to raise an approach to the advances from the normative and jurisprudential system, around family law and its adjustments to attenuate the difference of gender roles and stereotypes, constructed as a study analytical and descriptive of the legal section for gender equality.

Keywords: Family, Equality, Family Law, Family Models.

\section{Introducción}

Los avances en la consolidación del reconocimiento de los derechos humanos, en su propio proceso evolutivo y generacional, permite esbozar su impacto no solo en el robustecimiento del catálogo normativo, sino de acciones y políticas públicas de los estados para disminuir la brecha diferenciadora entre una realidad fáctica y del contenido del enunciado normativo.

Entre esos avances del catálogo de derechos fundamentales, más allá de la identificación generacional de derechos humanos, para el tema de análisis, se 


\section{http://revistainvestigacionacademicasinfrontera.com}

advierte el impacto por un reconocimiento protector para la familia, no sólo en intención de disminuir la tensión entre los roles de género de la pareja, al determinar que los roles asignados en el ejercicio de masculinidad y feminidad en la familia han sido reproductores de la dicotomía de los espacios públicos y privados en que aquellos se desenvuelven, como premisa diferenciadora que el sistema jurídico y las políticas públicas han tendido a disminuir, a fin de que se traduzca en el ejercicio de una maternidad y paternidad responsable, más plena, y en escenarios más igualitarios.

Además de lo anterior, se advierten los avances en el derecho, a propósito de los derechos emergentes, de la identidad de género, sin otro criterio diferenciador a la persona, y con ello los derechos que posee, en su condición de ser humano; desde esta concepción de igualdad, no discriminación, de desarrollo a plenitud, desde el asidero del grupo familiar; entorno desde el cual se advierte una evolución que impacta al concepto social tradicional. Los matrimonios igualitarios, las adopciones homoparentales, responden a una nueva realidad social y jurídica, y es en respuesta a ésta dinámica social, cómo el sistema jurídico se ha venido ajustando.

\section{Los modelos de familia}

El abordaje de la familia como objeto de estudio, se ha hecho desde una perspectiva biologicista, sociológica, religiosa, política, y jurídica. El estudio biológico revela a la función reproductiva de la mujer fecundada por el varón, generando así la gestación de otro ser, equiparándola a una unidad biológica. La posición sociológica la manifiesta como una institución social, representada por 


\section{http://revistainvestigacionacademicasinfrontera.com}

"cadenas fraternales" (Olegario Saucedo, en Romano Casas, 2016), que unen a sus individuos y que les caracteriza la solidaridad social.

La posición religiosa la vincula con un origen divino, como una institución de Dios, cuya unión del ser bisexuado es expresión del amor de Dios, y donde se cultivan los valores como la moral, la ética, el amor, la fraternidad, la solidaridad, la comunicación a los individuos y a los pueblos (Romano Casas, 2016). La corriente política, le da la perspectiva de institución, no solo como base de organización social, sino por las normas jurídicas que se implementan para su protección y del diseño de políticas públicas para la custodia estatal, sin pasar desapercibido que, como unidad social y económica, incide por sí misma en el desarrollo socioeconómico del Estado-nación.

Finalmente, el criterio jurídico descriptor de la familia, en sendos instrumentos nacionales como internacionales, la describe como el derecho humano y fundamental de la persona, y la obligación de su protección y tutela, regulando con ello, todas las consecuencias jurídicas gestados a partir del vínculo matrimonial, o de una "unión a él asimilada" (Romano Casas, 2016), que gesta las relaciones de parentesco, necesidades materiales y afectivas de sus miembros.

En otro sentido, debe advertirse el abordaje de la familia, como principio antropológico, dimensionado esto que "por intermedio de la familia, la vida humana adquiere dignidad, y de allí su inherente necesidad", además que son constitutivas del ser del hombre, y si éstas son alteradas o tergiversadas en sus cimientos, se generaría un serio obstáculo para el desarrollo de la identidad personal; y con ello, el aspecto relacional de hombre se vería alterado (Instituto de Ciencias para el Matrimonio y la Familia, 2013). 


\section{http://revistainvestigacionacademicasinfrontera.com}

Ahora bien, la dialéctica social ha partido siempre de la referencia de la familia como su unidad celular, su organización y estructura responde a los procesos de crianza, cuidado y protección de sus integrantes, los cuales son unidos no solo por los lazos de sangre, afectivos, civiles, que entrelaza la posibilidad de que sus miembros encuentren el sentido de pertenencia, de identidad, de acogida, y permite el desarrollo de sus potencialidades, el crecimiento personal, el vínculo fraterno que procura garantizar la relación afectiva, el respeto y la protección recíproca.

La familia para el derecho se encuentra tutelada, tanto a nivel nacional e internacional, y es referente para la conformación de una serie de vínculos tal es el caso del parentesco, la filiación, alimentos, tutela, patria potestad, manutención, nutrición material y afectiva, en una expresión amplia de la serie de derechos y obligaciones que de ello derivan.

Esta unidad social, de acuerdo con la Declaración universal de los derechos humanos, en su numeral 16.3 determina que: "es el elemento natural y fundamental de la sociedad y tiene derecho a la protección de la sociedad y del Estado" (Asamblea General de la Organización de las Naciones Unidas, 1948). Por su parte, la Declaración Americana de los derechos y deberes del hombre, artículo VI señala como un derecho fundamental el que: "Toda persona tiene derecho a constituir familia, elemento fundamental de la sociedad, y a recibir protección para ella", (Organización de Estados Americanos, 1948); como se advierte la familia es una estructura natural de organización social, que requiere protección, un derecho humano y fundamental. Esta característica de dinamismo opera en consonancia con los cambios propios de la sociedad, en su lógica mutable expresa reajustes 


\section{http://revistainvestigacionacademicasinfrontera.com}

organizacionales, de integración, incluso de fines, prevaleciendo la constante de la ayuda mutua.

La carta fundante mexicana, en su numeral cuarto le da una protección de alto orden al señalar que el varón y la mujer son iguales ante la ley y que ésta protegerá la organización y el desarrollo de la familia. En la regulación local, esto es, la codificación familiar del Estado de Sonora se define como "una institución de carácter social, constituida por la unión matrimonial o concubinaria de un hombre y una mujer, o por vínculos de parentesco en los tipos, líneas y grados que reconoce la ley" (Soto Lamadrid, 2011).

En la evolución del concepto de familia, se da cuenta no solo de este reconocimiento de los ajustes de su conformación, como se ha dicho, con una visión más amplia de familia; pues debe advertirse que la descripción anterior en la mayoría de los textos legales, se caracterizó por su sesgo ampliamente conservador, ya que en el enunciado normativo se expresó por la unión de hombre y mujer, con el objeto de perpetuar la especie, situaciones tales que han sido objeto de impugnaciones de las legislaciones locales, a través del ejercicio de la acción de amparo, como acción de tutela de la constitucionalidad, buscando la preservación de los derechos fundamentales, la dignidad humana. El objeto de la acción es la búsqueda de la protección frente a un discurso legislativo reproductor de los roles y estereotipos de género, la igualdad y los derechos humanos de los involucrados, pues posee un sesgo discriminador, a propósito del matrimonio igualitario.

Algunos de los elementos que están relacionados a la reconformación de las familias, son: Los roles de género, el retraso de la maternidad, el aumento de la cohabitación como inicio de la vida de pareja y de las uniones posteriores a la 


\section{http://revistainvestigacionacademicasinfrontera.com}

ruptura o divorcio, maternidades/paternidades sociales y biológicas, cambios económicos, e incluso de tendencias sociales, generan ajustes y reacomodos en las estructuras familiares y en la concepción de la misma.

Para contextualizar los modelos de familia sus expresiones contemporáneas, se retoma la propuesta del Dr. Miguel Ángel Soto Lamadrid (2011), quien identifica al menos cinco tipos de éste núcleo organizativo, tales son:

I.Familia patriarcal, extendida o polinuclear: es la integrada por una pareja conyugal o de hecho que convive con toda su descendencia (hijos, nietos y sus respectivos cónyuges). También entran en este concepto los núcleos familiares a los que se agregan otras personas vinculadas por lazos parentales o biológicos más alejados (tíos, abuelos, nietos, primos) o afectivos (ahijados, empleados domésticos, amigos).

II. Familia nuclear matrimonial con hijos: constituida por la pareja casada con hijos comunes.

III. Familia nuclear ensamblada o recompuesta: que se integra por un matrimonio que convive con sus hijos comunes y los hijos extraconyugales o de anteriores nupcias de cada uno, los que podrían ser adoptivos. En ésta hipótesis, las cargas matrimoniales incluyen las generadas por los hijastros que conviven en el mismo domicilio.

IV. Familia nuclear extramatrimonial: formada por la unión heterosexual, sin matrimonio, pero con hijos comunes, la que también puede constituir una familia extramatrimonial ensamblada, siempre que uno o ambos de los convivientes tuvieran hijos de uniones o matrimonios anteriores.

V. Familia monoparental integrada por el progenitor biológico y sus hijos: cuyo origen puede ser matrimonial o extramatrimonial, o producto de inseminación o fecundación asistida, que bien pueda manifestarse como una familia monoparental de origen adoptivo, que estaría formada por un hombre o una mujer con hijos de este origen. 
http://revistainvestigacionacademicasinfrontera.com

A ésta tipología de familias, debe adicionarse la familia homoparental, derivadas del matrimonio igualitario, es decir, el integrado por personas del mismo sexo, y la integración de los hijos sea por adopción, y a pesar de los vacíos legales, el uso de las técnicas de reproducción asistida, la inseminación artificial -homóloga o heteróloga-, e incluso a la gestación subrogada.

En relación a los matrimonios igualitarios, que en el cuerpo argumentativo de precedente jurisprudencial de décima época, en relación a la adopción por personas del mismo sexo, la Primera Sala de la Suprema Corte de Justicia de la Nación (2015, Tesis: 1a. CCCLIX/2015 (10a.), estableció que:

...la vida familiar de dos personas del mismo sexo no se limita a la vida en pareja, sino que, como cualquier pareja heterosexual, se puede extender, de así desearlo, a la procreación y la crianza de niños y niñas. También ha destacado que existen parejas del mismo sexo que hacen vida familiar con niños y niñas procreadas o adoptadas por algún miembro de la pareja, 0 parejas homosexuales que utilizan los medios derivados de los avances científicos para procrear o tienen hijos a través de la adopción, con independencia de que se le permita el acceso al poder normativo para contraer matrimonio. Ahora bien, una vez establecido que no existe razón constitucional para negar a las parejas del mismo sexo el acceso al matrimonio y que es discriminatorio crear una figura alternativa para ellas, esta Primera Sala determina que los matrimonios entre personas del mismo sexo tienen el derecho de ser considerados para adoptar, en igualdad de condiciones que los matrimonios entre personas heterosexuales $y$ cumpliendo con los requisitos pertinentes (cursivas propias).

Como se advierte la interpretación jurisdiccional materializa los principios de universalidad de los derechos humanos, de su condición de interdependientes e indivisibles, y al ser precisamente progresivos, denota una prohibición de no regresión, recayendo así en la salvaguarda de la igualdad, no discriminación, 


\section{http://revistainvestigacionacademicasinfrontera.com}

consecuentemente del respeto a la identidad sexual y a la dignidad humana, y del legítimo derecho y aspiración a conformar y cuidar el propio entorno familiar.

\section{La familia como derecho humano}

La naturaleza social del ser humano, la necesidad de pertenencia, de convivencia, de solidaridad y de identidad, permite reconocer a la familia como un derecho humano, fundamental, inherente a la persona, protegido por sendos instrumentos nacionales e internacionales ${ }^{2}$ donde advierten que éste derecho es mujeres y hombres -aunque con un propósito inclusivo solo debe hacerse referencia a la persona, prescindiendo de la distinción dicotómica basada en el sexo- para contraer matrimonio, elegir cónyuge, de la igualdad de derechos y responsabilidades durante la unión matrimonial -o de hecho-, a decidir el número y espaciamiento de los hijos.

En la posición interpretativa de la Primera Sala de la Suprema Corte de Justicia de la Nación (Protección de la familia como derecho humano en el derecho internacional, su contenido y alcance, 2012), el contenido y alcance de la familia como derecho humano, la explicitó con los siguientes elementos:

a) la familia es el elemento natural y fundamental de la sociedad y debe ser protegida por la sociedad y el Estado;

b) la familia y el matrimonio no son conceptos equivalentes, lejos de ello, el matrimonio únicamente es una de las formas que existen para formar una familia;

\footnotetext{
${ }^{2}$ El Art. 17 de la Convención Americana sobre Derechos Humanos señala que la familia debe ser protegida por la sociedad y el Estado. El Art. VI de la Declaración Americana de Derechos y Deberes del Hombre y el Art. 15 del Protocolo de San Salvador, también señalan el derecho a la protección de la familia y el Art. 4, inciso e) de la Convención Interamericana para Prevenir, Sancionar y Erradicar la Violencia contra la Mujer (conocida como Convención de Belém do Pará), establece el derecho de las mujeres a que se respete la dignidad inherente a su persona y que se proteja a su familia. (Badilla, 1996)
} 
http://revistainvestigacionacademicasinfrontera.com

c) el derecho de protección a la familia implica favorecer ampliamente el desarrollo y la fortaleza del núcleo familiar, mas no del matrimonio;

d) por el simple nacimiento de un niño, existe entre éste y sus padres un vínculo que implica vida familiar, donde el goce mutuo de la compañía constituye un elemento fundamental de aquélla, aun cuando la relación de los padres esté rota, por lo que medidas nacionales que limiten tal goce sí conllevan una interferencia al derecho a la protección de la familia; así, una de las interferencias más graves es la que tiene como resultado la división de una familia;

e) la Convención Americana sobre Derechos Humanos y el Pacto Internacional de Derechos Civiles y Políticos, reconocen como legítima la disolución del vínculo matrimonial, siempre y cuando se asegure la igualdad de derechos, la adecuada equivalencia de responsabilidades de los cónyuges y la protección necesaria de los hijos sobre la base única del interés y conveniencia de ellos; $y$,

f) ningún instrumento internacional en materia de derechos humanos ni sus interpretaciones, se pronuncian sobre procedimientos válidos 0 inválidos para disolver el vínculo matrimonial, lejos de ello, dejan en libertad a los Estados para que en sus legislaciones establezcan los que consideren más adecuados para regular las realidades propias de su jurisdicción, siempre y cuando ninguno de éstos se traduzca en un trato discriminatorio en los motivos o en los procedimientos.

Algunas de las características de las familias en México, de acuerdo al Instituto Nacional de Estadísticas y Geografía, a propósito de las estadísticas del día de las familias mexicanas de 2017, resaltan datos como:

a. Datos de la Encuesta Intercensal 2015, señalan que en México hay poco más de 31 millones de hogares. De ellos, $88.9 \%$ se conforman por individuos que guardan algún parentesco familiar entre sí, llamados "hogares familiares", que, por su definición, nos aproxima a hablar de "familias". Por otro lado, $10.8 \%$ no son familiares, es decir, son personas que viven solas, o con otras con quienes no guardan relación de parentesco con el jefe(a) de hogar. 
http://revistainvestigacionacademicasinfrontera.com

b. Para 2015, el $96.5 \%$ de la población se encuentra en un hogar familiar, el cual en promedio se conforma de 4.1 personas.

c. En 2015, del total de hogares familiares, siete de cada $10(69.7 \%)$ son nucleares, $27.9 \%$ ampliados y $1.0 \%$, son compuestos.

d. El hogar ampliado pasó de $26.6 \%$ del total de hogares familiares en 2010 , a $27.9 \%$ en 2015; los nucleares disminuyeron de 70.9 a 69.7 por ciento.

e. En $73.0 \%$ de los hogares familiares se reconoce como jefe a un hombre y en tres de cada 10 (27.0\%), es una mujer quien asume este papel.

\section{Criterios jurisprudenciales de protección a la familia ante los estereotipos de género y la diversidad}

Los avances normativos de protección a la familia han sido significativos, tanto desde el plano internacional -tratados bilaterales e instrumentos multilateralescomo nacional desde el cuerpo constitucional, código familiares o civiles, código penal, y sus normas adjetivas, Ley federal para prevenir y eliminar la discriminación, Ley de protección a las niñas, niños y adolescentes; Ley general de acceso a las mujeres a una vida libre de violencia, Ley del Instituto Mexicano de la Juventud, Ley para prevenir la violencia intrafamiliar, Ley de igualdad de hombres y mujeres, Ley de los derechos de los niños, niñas y adolescentes, entre otras (Departamento de Derecho Internacional OEA, 2017).

Referencia especial es el decreto de reformas y adiciones a la Constitución Mexicana, en materia de derechos humanos y sus garantías, en donde potencializa los derechos humanos a partir de establecer sus principios rectores de universalidad, interdependencia, indivisibilidad y progresividad; establece el 


\section{http://revistainvestigacionacademicasinfrontera.com}

principio pro persona ${ }^{3}$, la interpretación conforme, el control de la convencionalidad, y la obligación de indemnización de toda autoridad que viole los derechos humanos.

Constriñe a la autoridad al abordaje desde el criterio más amplio y protector, de identificación de las condiciones de vulnerabilidad, de discernir e intervenir a partir de las categorías sospechosas de exclusión -en razón de sexo, edad, discapacidad, identidad de género, nacionalidad, grupo étnico, condición de salud, religión, condición social, estado civil, opiniones, etc., (Poder Constituyente México, 2017)- discriminación o de sometimiento en relaciones de poder y jerarquía, de las relaciones humanas, a fin de construir escenarios más igualitarios de respeto a los derechos humanos.

Ciertamente el objetivo a alcanzar no es la proliferación de legislaciones que lleve a la expansión normativista, sino a mecanismos efectivos de protección, reconocimiento y ejercicio pleno de derechos, vinculado a políticas públicas desde los ámbitos que atiendan, en forma transversal, a mejorar las condiciones en los espacios alimentario, laboral, educativo, de seguridad social, vivienda, servicios de salud, inclusive, poblacionales donde se identifiquen la situación ya advertida de la diversificación y recomposición de la familia, y descritos todos, al menos como los propósitos del Plan Nacional de Desarrollo (2013-2018), como acciones estratégicas para el México incluyente, en paz, apoyos a grupos en vulnerabilidad, igualdad de género, combate a la pobreza, entre otros.

\footnotetext{
${ }^{3}$ [Un] criterio fundamental [que] [...] impone la naturaleza misma de los derechos humanos, la cual obliga a interpretar extensivamente las normas que los consagran o amplían y restrictivamente las que los limitan o restringen. [De esta forma, el principio pro persona] [...] conduce a la conclusión de que [la] exigibilidad inmediata e incondicional [de los derechos humanos] es la regla y su condicionamiento la excepción. (Piza Escalante Rodolfo) (Medellín Urquiaga, 2013)
} 


\section{http://revistainvestigacionacademicasinfrontera.com}

De suerte tal que, la intervención en el tema de familia, es un eje prioritario en el quehacer público, consecuentemente, en este acápite se planteó un acercamiento a la protección de éste grupo social, desde la perspectiva de la labor judicial; esto es, los criterios y precedentes jurisprudenciales a través de los cuales, el máximo órgano de interpretación judicial está incidiendo positivamente desde esta premisa de acción transformadora, tendiente no solo a protección de la constitucionalidad y con ello a la igualdad, como directriz sustantiva del sistema jurídico mexicano.

Bajo el principio fundamental de que estas acciones de interpretación judicial, en ésta consideración de aportar un plusvalor al sistema jurídico, trasciende al formalismo de la igualdad ante la Ley, sino que incide en forma decisiva en el camino hacia la igualdad de trato y resultados. En el seno de la familia, como una parcela de la realidad social, se conformó en un espacio reproductor de los roles y estereotipos de género, y auspiciado en la consideración de un espacio privado, potencializó las diferencias, tensionando los espacios de crianza y de cuidado, de provisión y protección, inclusive en la consideración sexuada y dicotómica de las relaciones.

Las herramientas legislativas, así como las políticas públicas y el redimensionamiento de los derechos humanos, junto con acciones más promisorias de protección, han gestado importantes precedentes jurisprudenciales que son referente para un litigio estratégico en tratándose del tema de familia.

Dos de los precedentes sustantivos para mejorar la igualdad en la familia, están relacionados, por un lado, a la contribución de la mujer en el sostenimiento 


\section{http://revistainvestigacionacademicasinfrontera.com}

del hogar hecho por conducto de dedicarse precisamente a su cuidado; $y$, por otro lado, el relativo a la violación en el matrimonio.

El primer precedente pronunciado bajo el Registro: 201634, como precedente pronunciado por el Tribunal Colegiado de Circuito, de Novena Época (1996), estableció en el cuerpo argumentativo que una de las manifestaciones del derechoobligación que se analiza es la relativa a la ministración de alimentos que la ley impone a los cónyuges; pero no se concreta exclusivamente a ese aspecto patrimonial, sino también a la ayuda de carácter moral y material que mutuamente deben dispensarse... la Suprema Corte de Justicia de la Nación ha considerado que es de sobra conocido que en la familia mexicana, por regla general, el hombre aporta los medios económicos para sufragar los gastos del hogar, en tanto que la mujer contribuye con el trabajo y el cuidado de la casa, la atención de los hijos y la administración doméstica; en consecuencia, este cuidado del hogar y la familia, deben ser considerados como los aportes de la mujer al matrimonio y familia.

Misma que fue corroborada con tesis jurisprudencial Registro: 2003217, de la Primera Sala, de abril de 2013, donde estipuló que los cónyuges deban darse alimentos, este deber constituye una obligación de carácter general que no hace distinción por razón de género, en tanto no prevé que uno de ellos en particular esté obligado a proporcionarlos, y al argumentar la mujer que se dedicó preponderantemente al trabajo del hogar o al cuidado y educación de los hijos, ya que en su matrimonio así se distribuyó la contribución de referencia, se presume que tal argumentación es cierta, y que tiene derecho, ante su necesidad alimentaria, a recibirlo, considerado aquello como su contribución; y en todo caso, recae la carga de la prueba en el otro cónyuge de demostrar lo contrario. Incluso, en diverso precedente, se estableció que aun cuando no exista cónyuge culpable en el divorcio, 


\section{http://revistainvestigacionacademicasinfrontera.com}

si una de las partes demuestra que durante todo el tiempo que duró su matrimonio civil se dedicó a la atención y cuidado de su hogar se debe reconocer la igual valía de la aportación del trabajo en el hogar para la consecución de los fines del matrimonio, ya sea que éste se haya desempeñado por el hombre o por la mujer (Tesis: XXXI.13 C (10ª .) Registro: 2003916).

En atención a la violación entre cónyuges, la interpretación judicial determinó que la institución del matrimonio tiene entre sus finalidades, la procreación de la especie, en virtud de lo cual, los cónyuges deben prestarse a la relación carnal, que como consecuencia lógica sólo concibe la práctica de la cópula normal; de tal manera que si el cónyuge la impusiera de manera anormal y violentamente, lesionaría la moral y la libertad sexual de su pareja, que en ningún momento consintió tales prácticas, y por ende, se configurará el delito de violación (Violación entre cóyuges, delito de., 2006).

La igualdad entre los cónyuges fue descrita como una obligación de Estado Mexicano, que debe custodiarse tanto durante el matrimonio como en la separación, razonamiento que se vierte al reconocer el papel central de la familia en la existencia de una persona y en la sociedad en general, esta igualdad de derechos y equivalencia de obligaciones entre los cónyuges, debe prevalecer durante el vínculo matrimonial como en la separación, de manera tal que está prohibido todo trato discriminatorio en lo que respecta a los motivos y los procedimientos de separación o de divorcio, incluidos los gastos de manutención y la pensión alimenticia, lo que desemboca en el deber del Estado de velar por que el divorcio no constituya un factor de empobrecimiento ni un obstáculo para el ejercicio de los derechos humanos, específicamente el derecho humano a un nivel de vida adecuado en 


\section{http://revistainvestigacionacademicasinfrontera.com}

relación con la obtención de los alimentos (Igualdad entre los cónyuges. Contenido y alcance, 2016).

Otra vertiente de los avances pro igualdad en el derecho de familia, es en relación a la guarda y custodia de los hijos, es importante reconstruir el argumento judicial en relación al caso, pues el Tribunal parte reconociendo que las legislaciones civiles -o de familia- otorgan preferencia a la madre en el otorgamiento de la guarda y custodia de los menores de edad se fundamentaba en una idea preconcebida, bajo la cual, la mujer gozaba de una específica aptitud para cuidar a los hijos... entre los análisis se vierten su inadmisibilidad ante el postulado del sistema jurídico de la igualdad entre hombres y mujeres como uno de los pilares fundamentales del sistema democrático. La tendencia clara, es de la participación y cooperación de ambos cónyuges a fin de realizar las tareas de la casa y el cuidado de los hijos.

A mayor abundamiento, es categórico el argumento único de la presunción de ser la madre la más apta y capacitada para el otorgamiento de la guarda y custodia, ello tiene sustento en la realidad social a roles y estereotipos sociales culturizado en la colectividad; sin embargo determina que es un hecho notorio que el funcionamiento interno de las familias, en cuanto a distribución de roles entre el padre y la madre, ha evolucionado hacia una mayor participación del padre en la tarea del cuidado de los menores, convirtiéndose en una figura presente, reconociendo y estimulando el órgano judicial la paternidad responsable, y despoja de preconcepciones para los análisis en escenarios que hacen prevalecer la igualdad e incide en disminuir las brechas del ejercicio de derechos y obligaciones en el ámbito de familia, (Principio de igualdad entre hombres y mujeres. El 
http://revistainvestigacionacademicasinfrontera.com

otorgamiento de la guarda y custodia de un menor de edad no debe estar basado en prejuicios de género, 2012).

Otro aspecto sustantivo en la cual se ha avanzado es en relación al matrimonio igualitario y la adopción por matrimonios homoparentales. En el primero bajo línea argumentativa de la igualdad y la dignidad humana, el respeto a la identidad de género y preferencia sexual, ha determinado la inconstitucionalidad de las legislaciones civiles o familiares al determinar que el matrimonio se contrae entre solamente por un hombre y una mujer, por lo que, señala el criterio ese poder únicamente puede ejercitarse para contraer matrimonio con alguien del sexo opuesto, es indudable que sí comportan en realidad una distinción basada en las preferencias sexuales, porque una persona homosexual únicamente puede acceder al mismo derecho que tiene una persona heterosexual, si niega su orientación sexual, lo que es precisamente la característica que lo define como tal; en ese sentido, permite utilizar el poder normativo para crear un vínculo matrimonial se apoya en las preferencias sexuales de las personas, trasgrediendo por tanto el principio de igualdad contemplado en el cuerpo constitucional, (Matrimonio entre personas del mismo sexo. Las normas civiles que definen la institución del matrimonio como la que se celebra entre un solo hombre y una sola mujer, contienen una distinción con base en una categoría sospechosa. , 2015).

En relación a la adopción, la Primera Sala de la Suprema Corte de Justicia en México (Adopción. Los matrimonios entre personas del mismo sexo tienen el derecho a ser considerados para realizarla en igualdad de condiciones que los matrimonios entre personas heterosexuales., 2015), señaló como argumento central que la vida familiar de dos personas del mismo sexo no se limita a la vida en pareja, sino que, como cualquier pareja heterosexual, se puede extender, de así desearlo, a la procreación y la crianza de niños y niñas. También ha destacado que 


\section{http://revistainvestigacionacademicasinfrontera.com}

existen parejas del mismo sexo que hacen vida familiar con niños y niñas procreadas o adoptadas por algún miembro de la pareja, o parejas homosexuales que utilizan los medios derivados de los avances científicos para procrear o tienen hijos a través de la adopción, con independencia de que se le permita el acceso al poder normativo para contraer matrimonio, ambas situaciones de la limitación de la adopción como el contraer matrimonio por personas del mismo sexo, son generadores de discriminación en igualdad de condiciones que las parejas heterosexuales, pues ésta condición de homosexualidad o de identidad de género es por sí misma uno de los presupuestos planteados como categorías sospechosas en el artículo primero constitucional.

La interpretación continúa construyendo espacios de igualdad, derribando constructos sociales incluso en el seno familiar, que supone es un espacio por excelencia para la realización humana. Los temas que continúan avanzándose son a guisa de ejemplo, en materia de la innecesaridad de invocar alguna causal de divorcio, tramitando la acción del divorcio sin expresión de causa, que se soporta en la prevalencia de la dignidad humana; en el acceso del varón a pensión alimenticia por parte de la pareja, a la posibilidad de acceder a prestaciones de seguridad social, como derechohabiente dependiente de la esposa.

El camino aun es largo por recorrer, y debe incidirse desde el proceso de culturización y formación desde el seno de la familia bajo la premisa del respeto y el reconocimiento del otro como igual; pues aun con los avances, prevalece el que las "mujeres enfrenten dificultades legales, prejuicios de los funcionarios y culpabilización social" (Torres Falcón, 2009). 
http://revistainvestigacionacademicasinfrontera.com

\section{Líneas para una conclusión}

Los avances en la consolidación del reconocimiento de los derechos humanos, en su propio proceso evolutivo y generacional, permite esbozar su impacto no solo en el robustecimiento del catálogo normativo, sino de acciones y políticas públicas de los estados para disminuir la brecha diferenciadora entre una realidad fáctica y del contenido del enunciado normativo y la forma de la relación intrafamiliar, doméstica, donde replica los constructos sociales de los roles y estereotipos de género, que pueden llegar a incidir negativamente en los derechos y desarrollo pleno de sus miembros.

La familia como grupo primario de organización social, sigue siendo considerada un elemento fundamental e insustituible en la formación de valores y núcleo de integración social, y en ella se encuentra manifestación de los vínculos social, jurídicos, económicos, culturales; en su propia dialéctica el entorno familiar ha mutado su forma nuclear paradigmática -padre, madre, hijos-, y en las últimas décadas, en consonancia con los avances de los derechos humanos, la dignidad humana, la inclusión y la tolerancia, se ha ajustado en función la diversidad de las relaciones interpersonales.

Ciertamente, al ser la familia la estructura social básica responde a los constructos que, el colectivo de pertenencia, en la época y lugar determinado, orientan y modelan en la construcción de género, de los roles y estereotipos que la femineidad y la masculinidad imponen; no obstante, los avances asincrónicos entre la realidad fáctica y jurídica, han exigido que el propio derecho de familia modifique los criterios de las normas en armonía a esta amplitud y diversidad, bajo criterios más incluyentes, igualitarios y democratizadores.

Aun cuando han sido significativo los avances normativos y sociales para que las personas puedan ejercer en plenitud, con libertad e independencia, el desarrollo de su vida 


\section{http://revistainvestigacionacademicasinfrontera.com}

y su papel en la familia, el camino es largo por recorrer, los esfuerzos del sistema jurídico, las políticas públicas, y los precedentes judiciales, aun no logran incidir para que la igualdad sea la constante, y requiere de un esfuerzo social mayúsculo que culturice desde este concepto de la igualdad y el respeto al otro.

\section{Fuentes consultadas}

Adopción. Los matrimonios entre personas del mismo sexo tienen el derecho a ser considerados para realizarla en igualdad de condiciones que los matrimonios entre personas heterosexuales., Registro: 2010482 (Primera Sala de la Suprema Corte de Justicia de la Nación Noviembre de 2015).

Asamblea General de la Organización de las Naciones Unidas. (10 de diciembre de 1948). Declaración Universal de los derechos humanos. Obtenido de http://www.ohchr.org/EN/UDHR/Documents/UDHR_Translations/spn.pdf

Badilla, A. E. (1996). El derecho a constitución y la protección de la familia en la normativa y la jurisprudencia del Sistema Interamericano de Derechos Humanos. Obtenido de http://www.corteidh.or.cr/tablas/a22086.pdf

Departamento de Derecho Internacional OEA. (1 de Noviembre de 2017). Derecho de familia y niñez. Obtenido de Red de Cooperación Jurídica Hemisférica en Materia de Derecho de Familia y Niñez: http://www.oas.org/dil/esp/derecho_de_familia_red_de_cooperacion_mexico_proc edimental.htm

Igualdad entre los cónyuges. Contenido y alcance, Registro: 2011231 (Primera Sala de la Suprema Corte de Justicia de la Nación Marzo de 2016).

Instituto de Ciencias para el Matrimonio y la Familia. (2013). Familia y Derechos Humanos. Chiclayo, Perú: Facultad de Derecho - Universidad Católica Santo Toribio de Mogrovejo.

Matrimonio entre personas del mismo sexo. Las normas civiles que definen la institución del matrimonio como la que se celebra entre un solo hombre y una sola mujer, contienen una distinción con base en una categoría sospechosa. , Jurisprudencia Registro: 2010676 (Primera Sala de la Suprema Corte de Justicia de la Nación Diciembre de 2015). 


\section{http://revistainvestigacionacademicasinfrontera.com}

Medellín Urquiaga, X. (2013). Principio pro persona. México: Suprema Corte de Justicia de la Nación.

México, Presidencia de la República, (2013), Plan Nacional de Desarrollo 2013-2018, fuente electrónica, disponible en: http://www.dof.gob.mx/nota_detalle_popup.php?codigo=5299465

Organización de Estados Americanos. (1948). Declaración Americana de los Derechos y Deberes del Hombre. Obtenido de Comisión Interamericana de los Derechos Humanos: http://www.oas.org/es/cidh/mandato/Basicos/declaracion.asp

Poder Constituyente México. (2017). Constitución Política de los Estados Unidos Mexicanos. México: Cámara de Diputados.

Principio de igualdad entre hombres y mujeres. El otorgamiento de la guarda y custodia de un menos de edad no debe estar basado en prejuicios de género, Registro: 2000867 (Primera Sala de la Suprema Corte de Justicia de la Nación Mayo de 2012).

PROTECCIÓN DE LA FAMILIA COMO DERECHO HUMANO EN EL DERECHO INTERNACIONAL. SU CONTENIDO Y ALCANCE, 2002008. 1a. CCXXX/2012 (10a.). (Primera Sala de la Suprema Corte de Justicia de la Nación Octubre de 2012).

Romano Casas, G. (2016). Familia y Homosexualidad. Estudio jurídico de México y el mundo. México: Porrúa.

Soto Lamadrid, M. A. (2011). Código de Familia para el Estado de Sonora. Exposición de motivos y texto integrado del codigo original y sus reformas. Hermosillo, Sonora: Beilis.

- - (2011), Síndrome de alienación parental y justicia restaurativa, México, 2011, Editorial Beilis

Torres Falcón, M. (2009). ¡Viva la familia! Un panorama de la legislación vigente en México. Alteridades, 41-54.

Violación entre cóyuges, delito de., Registro: 175717 (Primera Sala Febrero de 2006). 